\title{
Officials Reflections about Health Promoting Factors among Newly Arrivals - An Introductory Analysis
}

Heidi Carlerby ${ }^{{ }^{*}}$ and Mats Persson ${ }^{2}$

${ }^{1}$ Department of Health Sciences, Mid Sweden University, Sweden

${ }^{2}$ Headquarters, Policy and Plans Department, Swedish Armed Forces, Sweden

\begin{abstract}
Background: Resulting from conflicts, millions of peoples have been forced to leave their countries of origin. In Sweden, the Employment Agency is responsible for making decisions of immigrants' residence in municipalities and in co-operation with these allow the immigrants' establishment in the society. Preventive interventions among migrants and refugees, and health interventions in heterogeneous populations show that increased participation in society has positive imprints on health development. A new country includes getting acquaintance with non-familiar cultures. For example, other expectations on rules of gender, sickness, and illness. Recent years the low density populated areas in northern Sweden have received a high number of refugees in comparison with their population size. The purpose of this study was to explore how officials the Employment Agency and a selection of municipalities reflect over and define health promoting factors in their meetings with newly arrived.

Methods: All officials (N 68) in one of the four northern counties were invited to recording their reflections on health promoting factors close to their meetings with newly arrived. The officials recorded how they defined health promoting factors according to the Audit method. The data collection of experiences of importance considering health promotion and social determinants was collected by five focus group interviews with twenty-three officials.

Results: This study showed that the officials defined access to the health care, participation in the society, and sufficient collaboration between the authorities for not losing valuable time during the establishment period as imported factors for their clients' opportunities for health. The officials take power among males for given, while they more often reflected over lack of power among women. However, the Swedish ideal of gender as equal quite often a challenge the newly arrivals.
\end{abstract}

\section{Introduction}

In the light of the conflicts that resulted in an increasing refugee stream between 2013 to 2015, the Migration Agency radically increased the number of asylum places in the four most northern counties in Sweden (Jämtland, Västernorrland, Västerbotten, and Norrbotten). In 2015, an aggregate number of 51197 asylum seekers were allocated to the Swedish municipalities. From those, 4669 individuals $(9.1 \%)$ where allocated in the four northern counties [1]. In the present study one of those counties was selected for further investigations.

Individual's health status depends on several factors, which often are located outside the health and welfare organisation. Both the World Health Organisation (WHO) and the European Union (EU) recommend that health perspectives should be integrated into other policies of matter [2].

Refugees who suffer from poor health and in addition are partly linked to experiences in the country of origin and circumstances during the escape. Meta-analysis claim that $10 \%$ of the refugees, from whom have resettled in western countries, suffers from Post Traumatic Stress Disease (PTSD) [3].

The national Red Cross survey shows that about 30\% of the refugees that are coming to Sweden have experiences which can be of traumatising character [4].

Almqvist [5] have concluded that a holistic picture of the asylum seekers surrounding environment, including consideration of health promoting factors, are important for a favourable health. In addition, a holistic approach can help determine whether the prevention will succeed or not, and reduce symptoms and the risk of mental illness.
A study concerning health promoting and preventive interventions among migrant and refugees in heterogeneous populations in Denmark has shown that increased participation in the society has positive impacts on health development [6].

Sweden has more than 40 years' of experience receiving refugees. Over the years, the main responsibility for the issue has alternated between various organisations and authorities. From 1985, the highest authority was the Labour Market Board (AMS). Then followed a period when the anchorage to the labour market not was as clear, which was due to shared responsibility between several authorities. In 2010, the so-called establishment reform was implemented by the Swedish government which transferred the responsibility to the Employment Agency (EA). Accordingly, EA became responsible for refugees to establish themselves in the society. The newly arrived individuals have in frame of the establishment period of 24 months to integrate in the Swedish society. EA is responsible and for making decisions of immigrants' residence in municipalities [7]. The municipalities are responsible for that immigrants are given training in Swedish language, which is carried out under the programme "Swedish For Immigrants" (SFI), providing civic orientation (CO), practical help at

${ }^{*}$ Corresponding Author: Dr. Heidi Carlerby, Department of Health Sciences, Mid Sweden University, Sweden; E-mail: heidi.carlerby@muin.se

Citation: Carlerby H, Persson M (2017) Officials Reflections about Health Promoting Factors among Newly Arrivals - An Introductory Analysis. Int J Community Fam Med 2: 124. doi: https://doi.org/10.15344/2456-3498/2017/124

Copyright: (c) 2017 Carlerby et al. This is an open-access article distributed under the terms of the Creative Commons Attribution License, which permits unrestricted use, distribution, and reproduction in any medium, provided the original author and source are credited. 
Citation: Carlerby H, Persson M (2017) Officials Reflections about Health Promoting Factors among Newly Arrivals - An Introductory Analysis. Int J Community Fam Med 2: 124. doi: https://doi.org/10.15344/2456-3498/2017/124

Page 2 of 8

the residence, notify and help families with registration so that their children and adolescents have access to the school, as well as providing usual social service (Employment Agency, 2016).

Health promotion and prevention of illness provides benefits in both short and long term for the individual, but also for the society [8]. If the health of new arrivals is promoted, such as language and participation in the society, the possibility of a successful establishment increases. The core of the work taking care of newcomers, is that the circumstances for providing good health are important for the establishment in the community, such as participation in work, studies, or other daily activities that contribute to the society. A functioning migration process promotes health among the new arrivals and facilitate the establishment on the labour market [9]. Paying attention to determinants of health among newly arrived allows that skills to a greater extent can be exploited [6] and matched with the needs of the region's labour market [10]. Social constructions (SC) are not static, but dynamic processes that are reproduced, by the inhabitants in the society [11]. When SC are reproduced including dimensions of power that are dependent on gender, ethnicity, or socio-economical position, can affect an individual's opportunity to obtain good health [12]. The traditional gender rules, with expectations of the male as the breadwinner and the woman having core responsibility for the household [13], are currently not a norm in Western countries such as in Scandinavia who claims that they are gender equal. Both men and women participate somehow equally in the working life, while women still do more than half of the unpaid work in the households [14]. The level of collectivism such as loyalty to the family, necessity to sense of belonging to the group and sharing of values and norms, are high in the Arabic region [15] where the main part of the of newly arrived come from (Migration Agency, 2016). In Scandinavia it is the opposite, where the level of individualism is high [15]. Northern Sweden, as well as some other parts in Sweden, are struggling with an aura of exoticism, which bestowed advantages being captivating for tourists. However also disadvantages, where the inhabitants are pictured out by the urban population as old fashioned and as a burden that hampering the national growth [16].

A study within the Swedish context [17] shows that policy makers and civil society in some small rural municipalities consider the refugee reception as an opportunity to balance the population structure because such communities often have an ageing population and a declining population base. However, their research also shows that policy makers and the civilian population in other municipalities with similar social structure can have the opposite perception. In these cases, explanations are provided where such negative attitudes can be derived to lack of housing and jobs.

Research is needed regarding the health and future prospects among the newly arrived who settle outside the metropolitan areas of Stockholm, Gothenburg and Malmoe. However, there are not enough studies that illustrate how officials and specialists capture asylum seekers and the newly arrived strength and empowerment from a health promoting perspective, gender, and place of residence. To our knowledge, there have been no previous studies carried out where conditions in small municipalities and middle sized cities have been examined from using the health perspective delineated above.

Objectives The objectives of this study was to:

- explore how determinants for health were defined by officials and specialists at the Employment Agency and by the social officials at the municipalities
- $\quad$ illuminate the impact of gender and place of residence within the establishment program

\section{Methods}

\section{Description of the theoretical point of departure for choose of study design}

The theoretical starting point with this study is a from a holistic and thus from a systemic perspective. Accordingly, concerns that are analogous to systems thinking, which is occupied with interactions and relations among things and these things interactions with other things in its environment and with its environment itself [18]. This also apply to the mixed method according to Strandberg et al.; Bentzen $[19,20]$, and to help researchers achieve meta-inferences. Meta-inferences can be developed as concepts and their interrelation into a set of theoretical statements for a given substantive area or issue.

To use focus groups interviews in combination with Audit recording are preferable when interactive discussion with a specific focus and holistic covering would like to be reached [19]. In addition to the study results, participation in a focus group investigation has a value for the group members themselves [21] as it encourage to further discussion [19].

A use of mixed method is recommended as a complement to quantitative data collection when the researchers would like to capture a holistic understanding of the phenomenon of interest [22].

\section{The region and the participants}

The studies were conducted in a county with a huge area and low population density (11 inhabitants per square kilometre) located in the northern part of Sweden. This albeit there is a city near the coast with around 800 inhabitants per square kilometre.

This municipality hosts 97633 out of the counties 243897 inhabitants [23]. In the selected county it is most common to work in middle and small size enterprises or in official service. The consumption of health care services is higher than the country average as well as the unemployment rate. The amount of academics are lower than the country average [24].

All 68 officials and specialists from the Employment Agency engaged in the Establishment program and officials in the Municipality Social Offices located in the county's seven municipalities was invited to participate in the study. A majority of the officials had a university degree, and approximately half of them had worked four years or longer with newly arrived [25].

From here and onwards all respondents and informants are called "officials" and all newly arrived are called "clients."

\section{Quantitative data collection}

The Audit method that was used for the quantitative data collection is a scientific practical method for ensuring the quality of services provided, such as health care, counselling, or action plans. The method has its origin in the Danish primary health care and is developed by family doctors [20] and is originally designed for research and quantitative data collection. In addition, it is advantageous to combine the method with a relevant qualitative data collection [26]. Furthermore, the Audit method is described as an activity-based 
bottom up perspective, which aims for increasing the quality of operations through increased knowledge among the profession [26]. The uniqueness of the method is that it is not the patient/ client/resident who is the subject of recording, but the professionals' activities. Thus, the professionals' activities are recorded and then analysed to investigate which measures that are needed to take for improvement, for ensuring that improvement will happen, or alternatively confirmed so that activities are performed satisfactory.

The method comprises five main parts [26] figure 1):

a) To formulate goals for the business - increasing knowledge about how health-promoting factors are identified

b) To observe and record the participants own work - find out which tools that are used and how

c) Comparing the result with the set of formulated goals - analyse "b" to get a picture of how the work is done today

d) Changing the work so that the objectives are reached - take advice of the result of " $b+c$ " and in workshops share experiences and propose solutions to achieve "a"

e) Record whether change has occurred or not - repeat "b" about a year after " $d$ " has been implemented in the business to check if " $a$ " is reached.

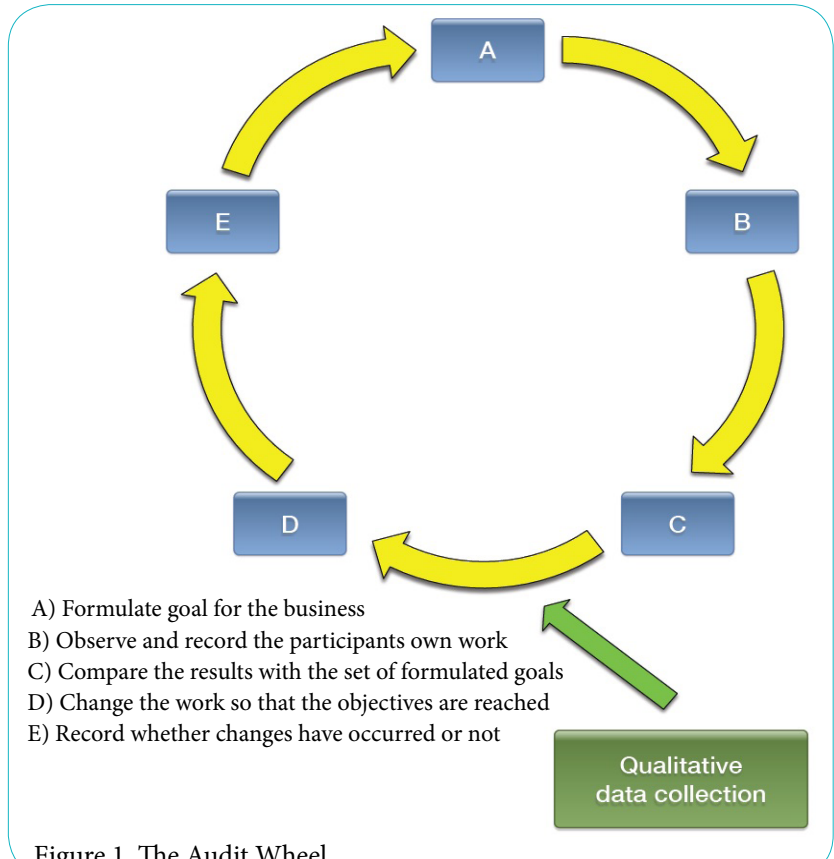

The Audit Wheel.

The recording form and a manual for the Audit-recording were created in co-operation with a selection of experienced specialists from the Employment Agency and the municipalities. The themes included in the recording form have their starting points from communication with practitioners, official reports, previous research and "salutogenic" approaches [27]. With a salutogenic approach, the objective is to contribute to and to promote social equity in health [28]. In addition, to include participation and empowerment [29]. In this study, the recording of the stage " $b$ " was approached as a recording of the officials' reflections after the meeting with the client. With respect to proper ethic rules, this issue was seriously highlighted in the manual. Thus, that it was the officials' reflections on health promoting factors that should be recorded, not mapping the clients.

The Audit investigation took place two weeks during spring 2016.

\section{Qualitative data collection}

After the preliminary results from the Audit-recording were available, a interview guide was created with support of experienced specialists to reach more information about areas that could be illuminated further and reach deeper understanding [21]. Thereafter, a pilot interview, supported by the question guide, was conducted with representatives from an Asylum Committee. The qualitative study include current municipal structures in the county, the large coastal town, coastal communities, and rural municipalities.

After considering the amount of data needed to reach on the one hand saturation, and on the other hand credibility, reliability, validity, [30] meta-interference and completeness [22], all with respect of available time to conduct data collection, the researcher in charge had to make priorities that resulted in that only four of seven municipalities was included in the inquiry. Accordingly, a new design was needed. The researcher in charge thus designed to invite officials from four out of seven municipalities to conduct interviews. Each interview began with a brief presentation of the results from the Audit-recording [19, $22]$ the activity is illustrated in figure 1.

The interviews took place during May, 2016 where twenty-three informants participated, fourteen women and nine men. Seventeen where officials at the EA and six where officials at the municipalities. The focus group interviews were conducted with three to seven informants in each group, and where conducted at the informants' regular workplace. The time of interviews ranged between 38-70 minutes in length and was recorded with the help of the principal investigator's "smart phone". In each interview session, an official from the County Administrative Board attended as an observer [21].

\section{Data analysis}

The Audit-recording was compiled and analysed using SPSS. ${ }^{1}$ Descriptive statistics were conducted by frequency analysis. Chisquare tests were used for analysis of variance between groups, depicted in table 2 and table 3. A p-value less than 0.05 was accepted as an indicator statistical significance [31]. The interviews were transcribed verbatim by the researcher in charge and analysed with inspiration of content analysis [30]. Manifest approach was used and the analyse units were sorted in according to the central questions in the interview guide:

- How has it influenced you by participating in the Auditrecording?

- Which results from the Audit-recording do you estimate as most important for your clients' health?

- How do you look upon the patterns that are revealed when considering gender and municipality types in the Auditrecording?

When paths and tendencies in the material were defined trough codes [21] the researcher in charge summarised and drew conclusions from the two conducted studies. The work with the meta-interference was initiated during a workshop that began with a result presentation of the studies conducted. During that workshop, results were presented and used as basis for discussions. However, the workshop included a broader audience than the for the study included officials [25]. Hence, analysis from the meta-interference is currently only partly conducted and therefore not included in this paper.

${ }^{1}$ SPSS is a registered trademark and copyrighted @ b by IBM Corp. 
Citation: Carlerby H, Persson M (2017) Officials Reflections about Health Promoting Factors among Newly Arrivals - An Introductory Analysis. Int J Community Fam Med 2: 124. doi: https://doi.org/10.15344/2456-3498/2017/124

Page 4 of 8

\section{Ethics}

The project took into account the Declaration of Helsinki Ethical Principles for good research; that is, the information requirement, the consent requirement, the confidentiality and use requirement were met satisfactorily [32]. The researchers were aware of the new arrivals vulnerable situation, which required rigorous awareness in all project components. The methods and approaches for the study were chosen with respect to the newly arrived vulnerability. The study has been presented with no major objections for the Mid Sweden University's ethics committee (MIUN 2016/656).

\section{Results}

\section{Audit-registration}

Basics about the reflections: Thirteen out of 68 invited officials could participate in the Audit-survey. Those officials made N 120 reflections (recordings), n 47 in the large coastal municipality, n 40 in coastal municipalities and $\mathrm{n} 33$ where made in rural municipalities. Eight out of ten $(83 \%)$ reflections was made around clients they have meet at least once before. Half of the clients were females and half males. The median age for the clients was 32 years old (born 1984), the average age was 36 (born 1980). The oldest client was born in year 1949 and the youngest in 1997.

Included health factors: The health factors was categorized in nine themes and have 24 items (table 1). All frequencies are based on the 120 recorded reflections. In the theme of ongoing contact, there was high frequency for occupation/activities (69.2\%) and low frequency for non-governmental organizations (NGO) (7.5\%). Other health factors that had low frequency of inclusion was found under the theme of Social networks and the items hobbies/culture/religious societies (4.2\%), as well as under the theme Risk and the item lifestyle behaviours (11.7\%).

\begin{tabular}{|c|c|c|c|}
\hline Health factors N 120 & n (\%) & Health factors N 120 & n (\%) \\
\hline \multicolumn{2}{|l|}{ Ongoing contacts } & Economy & \\
\hline Insurance Agency & $51(42.5)$ & Satisfactory & $27(22.5)$ \\
\hline NGO & $9(7.5)$ & Improvement needed & $63(52.5)$ \\
\hline Occupation/activity & $83(69.2)$ & Risk & \\
\hline Health- and sick care & $47(39.2)$ & Lifestyle behaviours & $14(11.7)$ \\
\hline \multicolumn{2}{|l|}{ Social network } & \multicolumn{2}{|c|}{ Kom. Fam. Count. Orig. } \\
\hline Majority population & $16(13.3)$ & Regularly & $40(33.3)$ \\
\hline $\begin{array}{l}\text { Hobbies/Culture/ } \\
\text { Religion }\end{array}$ & $5(4.2)$ & Seldom/none & $28(23.3)$ \\
\hline Work-/study fellows & $45(37.5)$ & \multicolumn{2}{|l|}{ Physical activity } \\
\hline Neighbours & $44(36.7)$ & Exercising & $19(15.8)$ \\
\hline \multicolumn{2}{|l|}{ Security/trust } & $\begin{array}{l}\text { House-/physical } \\
\text { work }\end{array}$ & $37(30.8)$ \\
\hline Surrounding society & $29(24.2)$ & Walking/play & $24(20.0)$ \\
\hline Authorities & $54(45.0)$ & \multicolumn{2}{|l|}{ Participation } \\
\hline Neighbourhood & $55(45.8)$ & Power & $54(45.0)$ \\
\hline \multicolumn{2}{|l|}{ Family relations } & Self-confidence & $45(37.5)$ \\
\hline Resource & $34(28.3)$ & Proudness & $42(35.0)$ \\
\hline $\begin{array}{l}\text { Improvement } \\
\text { potential }\end{array}$ & $61(50.8)$ & & \\
\hline
\end{tabular}

When a separate analysis for females and males were made (table 2), it was revealed that under the theme Physical activity the factor household work/physical work was significantly more common in reflections among females in comparison with males ( $p$-value $=<0.001)$. Power was also a factor included more frequently in reflections regarding variations between females and males ( $p$-value $=0.011)$. No significant gender variance was shown in the theme of family relations.

\begin{tabular}{|l|l|l|l|}
\hline Health factors N 120 & Male n 62 (\%) & Female n 58 (\%) & $p$-value \\
\hline Family relation & \multicolumn{3}{|l|}{} \\
\hline Improvement needed & $27(43.5)$ & $34(58.6)$ & 0.099 \\
\hline Resource & $22(35.5)$ & $12(20.7)$ & 0.072 \\
\hline Physical activity & $7(11.3)$ & $12(20.7)$ & 0.159 \\
\hline Exercising & $9(14.5)$ & $28(48.8)$ & $<0.001$ \\
\hline House-/physical work & $10(16.1)$ & $14(24.1)$ & 0.273 \\
\hline Walking/play & \multicolumn{5}{|l}{} \\
\hline Participation & $21(33.9)$ & $33(56.9)$ & 0.011 \\
\hline Power & $23(37.1)$ & $22(37.9)$ & 0.925 \\
\hline Self-confidence & $21(33.9)$ & $21(36.2)$ & 0.780 \\
\hline Proudness
\end{tabular}

Table 2: Selection of included health factors in number and percent (\%) for females and males.

In separate analysis for type of municipality (table 3) shows variations in factors that were included in the reflections. Significant variance was shown between types of municipality regarding majority population $(p$-value $=0.016)$ in the large coastal municipality and neighbours ( $p$-value $<0.001$ ) in rural municipalities. Significant variance was shown in the theme Surrounding society $(\mathrm{p}$-value $=$ 0.044 ) and Neighbourhood ( $p$-value $<0.001$ ) as more frequent to include in rural municipalities, including Authorities ( $p$-value = 0.001 ) was more frequent in the other two types of municipalities. Coastal municipalities shows significant lower frequency to include Improvement in economy is needed ( $p$-value $=0.002$ ), but higher frequencies including Self-confidence $(p$-value $<0.001)$ and Proudness $(p$-value $=0.001)$. Power $(p$-value $=0.002)$ was more frequent in ruraland coastal municipalities compared to the large coastal municipality.

\section{Focus group interviews}

The officials expressed that they had ameliorated the necessity, and their awareness about health promoting factors thanks to their participation in the Audit-registration. During the Audit-registration, the health factors regarding the clients' social situations were fragmented. However, during the process social situations could be split into smaller and more manageable pieces that were discussed one by one. Therefore, the clients' social situation could be viewed upon in a positive way such as having an existing access to social and human capital. Nevertheless, this was nothing the officials had considered earlier during their daily work. On the contrary, under ordinary work where the social situation was included it was associated as a negative factor or as a dilemma. Few had included life style factors in their reflections. In addition, several officials' claimed that it is private and can be a topic for discussion only when they had met a client several times and they had been able to build common trust between each other. 
Citation: Carlerby H, Persson M (2017) Officials Reflections about Health Promoting Factors among Newly Arrivals - An Introductory Analysis. Int J Community Fam Med 2: 124. doi: https://doi.org/10.15344/2456-3498/2017/124

Page 4 of 8

\begin{tabular}{|c|c|c|c|c|}
\hline Health factors N 120 & $\begin{array}{l}\text { Large Coastal Municipality } \\
\text { n } 47(39.2 \%)\end{array}$ & $\begin{array}{l}\text { Coastal Municipalities } \\
\text { n } \mathbf{4 0}(\mathbf{3 3 . 3} \%)\end{array}$ & $\begin{array}{l}\text { Rural Municipalities } \\
\text { n } 33(27.5 \%)\end{array}$ & p-value \\
\hline \multicolumn{5}{|l|}{ Social network } \\
\hline Majority population & $11(23.4)$ & $1(2.5)$ & $4(12.1)$ & 0.016 \\
\hline Hobbies/culture/religion & $1(2.1)$ & $1(2.5)$ & $3(9.1)$ & 0.250 \\
\hline Work-/study fellows & $18(38.3)$ & $16(40.0)$ & $11(33.3)$ & 0.834 \\
\hline Neighbours & $17(36.2)$ & $5(12.5)$ & $22(66.7)$ & $<0.001$ \\
\hline \multicolumn{5}{|l|}{ Safety/trust } \\
\hline Surrounding society & $6(12.8)$ & $11(27.5)$ & $12(36.4)$ & 0.044 \\
\hline Authorities & $27(57.4)$ & $21(52.5)$ & $6(18.2)$ & 0.001 \\
\hline Neighbourhood & $17(36.2)$ & $12(30.0)$ & $26(78.8)$ & $<0.001$ \\
\hline \multicolumn{5}{|l|}{ Economy } \\
\hline Satisfactory & $8(17.0)$ & $14(35.0)$ & $5(15.2)$ & 0.067 \\
\hline Improvement needed & $28(59.6)$ & $12(30.0)$ & $23(69.2)$ & 0.002 \\
\hline \multicolumn{5}{|l|}{ Participation } \\
\hline Power & $13(27.7)$ & $19(47.5)$ & $22(66.7)$ & 0.002 \\
\hline Self-confidence & $17(36.2)$ & $24(60.0)$ & $4(12.1)$ & $<0.001$ \\
\hline Proudness & $17(36.2)$ & $21(52.5)$ & $4(12.1)$ & 0.001 \\
\hline
\end{tabular}

Table 3. Selection of included health factors in number and percent (\%) for different municipality types.

"It has enhanced the picture of how important it is to identify health promoting factors. I've gotten me a lesson. I'm happy for the process."

\section{Clients' value of importance of health}

The officials claim that the most important for their client's health is that the processes regarding health care need to go faster and the structures for collaboration with the health care departments at the county councils need huge improvement. The officials express frustration regarding that their clients got caught by the situation, and that they were exposed to unnecessary pain of both physical and psychological character because of insufficient collaboration between the responsible authorities.

"We would like to say to the one responsible at the Refugee Camp 'This person feel ill, you have to take contact with the health care service now!' Then the person can be treated, and feel better when they are coming to us who work with the establishment program. The time is running, and we can't take decisions without loosing valuable time for the newly arrived."

\section{Patterns between female and male about power}

The variations in the reflections regarding power and gender explains by the informants with as a majority if the officials was of Swedish origin, their assumptions regarding power are founded in the Swedish social constructions of culture and they took for given that their male clients have power. For women it could look very different from case to case. More often the officials reflects around lack of power among their female clients, and a changes in relation to power since they arrived to Sweden as compare to how it was when they lived in their country of origin.

“That we more often include reflections over women's de facto 'power' than for men, which may depend on that men have power. It mirrors more of what we are thinking than how things are in reality."
The informants was not in consensus with this description. Intensive discussions regarding gender and power occurred. However, all officials where in consensus that they have meet clients of both gender that was confused regarding the differences in gender rules in Sweden as compared to their country of origin.

"It can be a hard situation for a man who has had the position as the breadwinner, to arrive here and accept that women receive the equal amount of economic supply and opportunities as the man. It is a huge conversion for a man no longer have control over everyday life."

"Many young women who do not have a family have already pointed out their way when they are coming. They know what they would like to reach. There are all variations."

Several officials who have foreign background themselves, described how they have expired that time is needed to understand and adopt to the Swedish model for gender rules and routines for how to achieve a functional family life in Sweden. For example, that it is a necessity that both parents share the responsibility for care of children and home for to have a functional everyday life. This because both parents are expected to have activities outside the home such as work, school, or practice. Same informants described with confidence how they used their own experiences when explaining for their clients' the strength with gender equity. That the whole family, especially the children, are "winners" with gender equity.

"It's just a matter of time for the newly arrived before they recognize that if you want to have a good life here in Sweden, all parties get profit from equality."

\section{Patterns in reflections in relation to the kind of municipality}

The variation regarding trust to the authorities explains by the officials with; in rural municipalities just a few authorities are represented and the connections between the officials at the different authorities are closer. This lack of local authorities in rural 
municipalities is described by the officials as both positive and negative. It was positive that they easily could build up trust and familiarity with the clients, and it gave the officials a holistic picture of each individual client. On the other hand, the lack of authorities in the rural municipalities increased the burden for the officials, as they often where forced to help clients with issues that were another authority's responsibility. However, this condition also leads to that the officials had less time to deal with issues actually included in their duties. The more common reflections regarding contacts with neighbours in rural municipalities were exploring with that it are easier to get acquaintance with each other, and people are more eager to welcome newly arrived in small societies than in higher density populated areas. There was a huge variation between the types of municipalities if the officials had included trust in the neighbourhood or not. In all; however, officials described trust in the neighbourhood as a physical issue dealing with public communications. As the county has a huge area, with long distance between the central societies and low frequency of local buses, it was time-consuming for the clients. This amount of time consumption was necessary for the officials to consider when planning for their clients' activities in the establishment program.

\section{Discussion}

This study showed that the officials defined access to the health care, participation in the society, and sufficient collaboration between the authorities for not losing valuable time during the establishment period as important factors for their clients' opportunities to achieve good health. As the officials mentioned, insufficient collaboration might benefit from specific preventive guidelines for immigrants and refugees as described by Tugwell, et al. [33]. In addition, the officials claim that there is a need to consider the strength that can be achieved by more distinct descriptions by which authority that is ultimately responsible for each part of a client's integration in the society. Thus, existing national recommendations, methodological support, and local agreements where local authorities are supposed to co-operate to promote a client's integration in our society seem to have potential to develop [34]. Accordingly, the methodological support has to more explicitly consider how every client can achieve participation to develop empowerment [29], self-confidence, and pride to successfully integrate in the society viewed as a whole, as well as with a salutogenetic approach [27]. Furthermore, the Swedish ideal by claiming that social constructions of gender as equal [14] is quite often a challenge for the clients. The shown results regarding the struggling with social constructions of gender are in close connection to country of origin as well as country of destination are confirmed by Llácer et al. [13]. Another challenge for the newly arrivals concerning social constructions of culture are the different experiences by originating from regions with high level of collectivism compared to Scandinavian countries with high level of individualism [15]. These differences seem however, to appearer more seldom in rural areas. This equalisation in gap between collectivism versus individualism in the constructions of culture that might occur in peripheral areas are delineated as having a so called old fashioned social construction of culture [16]. However, this probably only exist as exotic in the same manner as some sub-urban metropolitan areas of Sweden are described "as a theatre scene with no actors" [35]. Maybe the newly arrivals, nor the so called "Norrlanders" recognise themselves in that comparison, but may be closer to their essential core values of life and family. The newly arrivals feel high confidence to the single officials and the newly arrivals tend to adapt well in northern Sweden, despite that the poor infrastructure may hamper their integration process. In the families with children, easily got access to the civil society and thereby improved their language skills and bicultural competences much faster as compared to newly arrivals who resettled in metropolitan areas. Mentioned health promoting factors make sense also in the long term perspective as it will assure that the children of migrated parents in future effectively will contribute to the society [9]. Municipalities with a long tradition of taking in refugees highlights the positive reception of refugees for humanitarian reasons and that society has a responsibility to defend people in need. However, it can be difficult for adults to find suitable jobs and opportunities for studies in small rural municipalities than in larger communities [17]. Present study, was conducted in an area where fewer inhabitants than the country average has a university degree, especially males [24]; therefore, it occurs competitions in job opportunities between the local population and the newly arrivals. This often is related to the heterogeneous group of immigrants who are over-represented having manual skills [10].

The selected study design with option to include a pre-designed mixed-method gave advantages inform of a clear rational to follow though each part of the study. However, the reference officials whom were involved during the whole study gave reliability, validity and credibility[30] to that this studies results are in line with what the officials are struggling with in their daily work at the Employment Agencies and municipality social offices. Stage "d" in the Auditmethod [26] equal as meta-interference according to Venkatesh et al. (2013) [22] is somehow initiated inform of a workshop for all stakeholders in a broader project named "Establishment with health perspectives". The County Administrative board was responsible for the workshop, and they as well as all involved stakeholders have received a comprehensive project report [25] where suggestions for implications are included. The report will also be used as base for further development of practice tools for the officials. Viz., a continuation of the work to reach meta-interference. To measure and ensure the impact of proposed and implemented actions stage "e" in the Audit method the principal investigator at Mid Sweden University will apply for additional funds to carry out a follow-up Audit-recording spring 2018. One of the weaknesses with this study was that only thirteen out of 68 officials participated in the Auditrecording (120 reflections) which might influenced the result. Of that reason the results must be considered with attention. However, the rich material that was achieved trough the focus groups interviews brought completeness to study purpose [26].

\section{Conclusions}

For to reach increased effectiveness within the establishment program, and decreased loss of time that risk to worsen the newly arrivals health, improved collaboration is needed. The collaboration between the responsible authorities regarding health promotion would gain by improved methodical support and development of comprehensive guidelines for health care professionals working with newly arrivals. Some of the participating officials whom themselves had migrated stresses that the whole family, especially the children gains by gender equity. The officials in general also stress how important it is to find a balance between promotion of gender equity, and showing the newly arrivals respect for their social constructions of culture in their country of origin. In northern Sweden the newly arrivals seems to quite easily get access to the civil society. The officials claims that the majority population in northern Sweden care about vulnerable individuals, and are willing to support the newly arrivals integration as they also look upon them as an potential resource for 
Citation: Carlerby H, Persson M (2017) Officials Reflections about Health Promoting Factors among Newly Arrivals - An Introductory Analysis. Int J Community Fam Med 2: 124. doi: https://doi.org/10.15344/2456-3498/2017/124

Page 7 of 8

regional survival and development. Irrespectively of if you are newly arrived, official or of the majority population the distance in sparsely populated areas are time consuming, and always need to be considered in the everyday life.

\section{Author Contributions}

The main hypothesis and the research idea was initiated by HC, who was the mentor and the supervisor of this research. HC has contributed substantially in data collection, analyses, and preparation of the first draft. The final draft was prepared in cooperation by HC and MP, and was edited by MP before submission.

\section{Competing Interests}

The authors declare that they have no competing interests.

\section{Funding}

This study was partly funded by Västernorrland County Administrative Board according to grant number 851-5587-15 assigned to Heidi Carlerby, Mid Sweden University, Department of Health Sciences.

\section{Acknowledgements}

First, we would like to thank all officials that shared all their knowledge from working with newly arrived, for sharing their time with us by their contributions, and by their invaluable everyday work.

Second, we would like to express our warmest thanks to Helena Hill, Åsa Nagrell, Jeanette Södermark, and Magda Åström who continuously contributed during the project period with high expertise, for sharing invaluable facts, and knowledge that we could use as basis when formulating the study.

Finally, we want to thank the project manager for "Establishment with Health Perspectives" - Runa Ödlund, Västernorrland County Administrative Board, who kept everything in the project together in a brilliant way.

\section{References}

1. Migration Agency (2016) Statistics.

2. Leppo K, Ollila E, Pe'na S, Wismar M, Cook S (2013) Health in All Policy Seizing opportunities, implementing policies.

3. Fazel M, Wheeler J, Danesh J (2005) Prevalences of serious mental disorders in 7000 refugees resetteled in western countries: a systematic review. Lancet 365: 1309-1314.

4. Tinghög P, Arwidson C, Sigvardsdotter E, Malm A, Saboonchi F (2016) Nyanlända och asylsökande i Sverige: En studie av psykisk ohälsa, trauma och levnadsvillkor. Report 2016:1, Röda Korsets Högskolas rapportserie, ISBN978-91-983684-0-6.

5. Almqvist K (2013) Effekter av långvarig extreme stress på relationer mellan föräldrar och barn. Lund: Studentlitteratur.

6. Ladekjær Larsen E, Stock C (2010) Capturing contrasted realities: integrating multiple perspectives of Danish community life in health promotion. Health Promot Int 26:14-22.

7. Sarstrand Marekovic M (2011) Från invandrarbyrå till flyktingmottagning fyrtio års arbete med invandrare och flyktingar på kommunal nivå. Doctoral dissertation, Linnaeus University. Växjö.

8. Nutbeam D (1998) Health promotion glossary. Health Promotion International 13.
9. Hernandez D, Macartney S, Blanchard V (2010) Children of Immigrants: Family and Socioeconomic Indicators for Affluent Countries. Child Indicator Research 3: 413-437.

10. Ambrosini M (2013) Immigration in Italy: Between economic acceptance and political rejection. Journal of international migration and integration 14: 175-194.

11. Burr V (1995) An introduction to social constructionism. London: Routledge, ISBN 0415104041 (hbk.).

12. Bécares L, Stafford M, Nazroo J (2009) Fear of racism, employment and expected organizational racism: their association with health. The European Journal of Public Health 19: 504-510.

13. Llácer A, Zunzunegui MV, Del Amo J, Mazarrasa L, Bolumar F (2007) The contribution of a gender perspective to the understanding of migrants' health. Journal of Epidemiology and Community Health 61 suppl 2: ii4-ii10.

14. Hagqvist $E$ (2016) The juggle and struggle of everyday life. Gender, division of work, work-family perceptions and wellbeing in different policy contexts. Doctoral dissertation, Mid Sweden University, Östersund.

15. Hofstede GH, Hofstede GJ, Minkov M (2010) Cultures and organizations: software of the mind : intercultural cooperation and its importance for survival. 3rd ed ed., New York: McGraw-Hill.

16. Eriksson M (2010) "People in Stockholm are smarter than countryside folks"-Reproducing urban and rural imaginaries in film and life. Journal of Rural Studies 26: 95-104

17. Lidén G, Nylén J (2014) Reception of refugees in Swedish municipalities: evidence from comparative case studies. Migration and Development 4 DOI: 10.1080/2163234.2014.894178.

18. Ackoff RL (1999) Ackoff's best: his classic writings on management. New York: Wiley, ISBN 0-471-31634-2.

19. Strandberg EL, Ovhed I, Borgquist L, Wilhelmsson S (2007) The perceived meaning of a $(w)$ holistic view among general practitioners and district nurses in Swedish primary care: a qualitative study. BMC family practice 8: 1.

20. Bentzen N (1993) Medical Audit - The APO-Method in General Pratice Scandinavian Journal of Health Care 1: 13-18.

21. Wibeck V (2010) Fokusgrupper: om fokuserade gruppintervjuer som undersökningsmetod. Lund: Student litteratur.

22. Venkatesh V, Brown S, Bala H (2013) Bridging the Qualitative-Quantitative Divide: Guidelines for Conducting Mixed Methods Research in Information Systems. MIS Quarterly 37: 21-54.

23. SCB (2016) Population statistics.

24. Sveriges kommuner och Landsting (2016) SALAR.

25. Carlerby H (2016) Hur handläggare/specialister inom etableringen definierar hälsofrämjande faktorer I möten med nyanlända: Ett delprojekt "Etablering med hälsoperspektiv". Project report, Dept. of health sciences, Mid Sweden University, Sundsvall.

26. Gilså Hansen D, Erisson T, Toft B, Schæfer K, Damsgaard J, Munch A (2005) Audit efter APO-metoden. Odense: Audit Projekt Odense (APO).

27. Eriksson M, Lindström B (2008) A salutogenetic interpretation of the Ottawa Charter. Health Promotion International.

28. Dahlgren G, Whitehead M (2007), Policies and strategies to promote social equity in health, Background document to WHO - Strategy paper for Europe, Institute for future studies.

29. Spretizer G (1995) An Empirical Test of a Comprehensive Model of Intrapersonal Empowerment in the Workplace. Am J Community Psychol 23: 601-629.

30. Graneheim U, Lundman B (2004) Qualitative content analysis in nursing research: Concepts, procedures and mearures to achieve trustworthiness. Nurses EducationToday 24: 105-112.

31. Pallant J (2012) SPSS Survival manual. 3rd ed., Berkshire,UK: Mc Graw Hill, Open University Press.

32. Hermerén G (Ed.) (2011) Good reseach practice - TheSwedish Research Council's expert group on ethics. Stockholm: Swedish Research Council. 
Citation: Carlerby H, Persson M (2017) Officials Reflections about Health Promoting Factors among Newly Arrivals - An Introductory Analysis. Int J Community Fam Med 2: 124. doi: https://doi.org/10.15344/2456-3498/2017/124

Page 8 of 8

33. Tugwell P, Pottie $K$, Welch V, Ueffing $E$, Chambers A, Feightner J

(2011) Evaluation of evidence-based literature and formulation of recommendations for the clinical preventive guidelines for immigrants and refugees in Canada. CMAJ 183: E933-E938.

34. Employment Agency (2016) Utgångspunkter för lokala överenskommelser om nyanländas etablering. Report Rev.3, Arbetsförmedlingen, Stockholm.

35. Molina I (2007) Intersektionella Rumsligheter. Tidskrift för genusvetenskap 3: 7-21. 